\title{
Overcoming Barriers to Technology Adoption in Small Manufacturing Enterprises (SMEs)
}

\author{
Len Estrin \\ John T. Foreman \\ Suzanne Garcia
}

June 2003

\footnotetext{
TECHNICAL REPORT

CMU/SEI-2003-TR-012

ESC-TR-2003-012
} 



\section{Overcoming Barriers to Technology Adoption in Small Manufacturing Enterprises (SMEs)}

CMU/SEI-2003-TR-012

ESC-TR-2003-012

Len Estrin

John T. Foreman

Suzanne Garcia

June 2003

Technology Insertion Demonstration and Evaluation Program 
This work is sponsored by the U.S. Department of Defense. The Software Engineering Institute is a federally funded research and development center sponsored by the U.S. Department of Defense.

Copyright 2003 by Carnegie Mellon University.

NO WARRANTY

THIS CARNEGIE MELLON UNIVERSITY AND SOFTWARE ENGINEERING INSTITUTE MATERIAL IS FURNISHED ON AN "AS-IS" BASIS. CARNEGIE MELLON UNIVERSITY MAKES NO WARRANTIES OF ANY KIND, EITHER EXPRESSED OR IMPLIED, AS TO ANY MATTER INCLUDING, BUT NOT LIMITED TO, WARRANTY OF FITNESS FOR PURPOSE OR MERCHANTABILITY, EXCLUSIVITY, OR RESULTS OBTAINED FROM USE OF THE MATERIAL. CARNEGIE MELLON UNIVERSITY DOES NOT MAKE ANY WARRANTY OF ANY KIND WITH RESPECT TO FREEDOM FROM PATENT, TRADEMARK, OR COPYRIGHT INFRINGEMENT.

Use of any trademarks in this report is not intended in any way to infringe on the rights of the trademark holder.

Internal use. Permission to reproduce this document and to prepare derivative works from this document for internal use is granted, provided the copyright and "No Warranty" statements are included with all reproductions and derivative works.

External use. Requests for permission to reproduce this document or prepare derivative works of this document for external and commercial use should be addressed to the SEI Licensing Agent.

This work was created in the performance of Federal Government Contract Number F19628-00-C-0003 with Carnegie Mellon University for the operation of the Software Engineering Institute, a federally funded research and development center. The Government of the United States has a royalty-free government-purpose license to use, duplicate, or disclose the work, in whole or in part and in any manner, and to have or permit others to do so, for government purposes pursuant to the copyright license under the clause at 252.227-7013.

For information about purchasing paper copies of SEI reports, please visit the publications portion of our Web site (http://www.sei.cmu.edu/publications/pubweb.html). 


\section{Table of Contents}

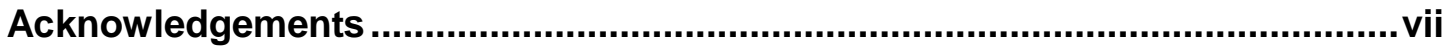

Executive Summary...................................................................................... ix

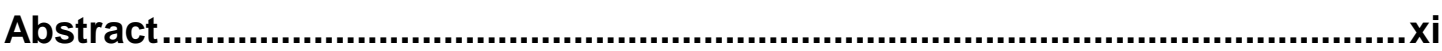

1 SMEs and the Defense Industrial Base ..................................................... 1

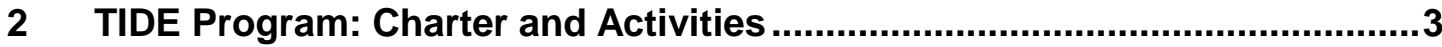

2.1 The TIDE Mission .........................................................................

2.2 TIDE Organization and Operation .................................................

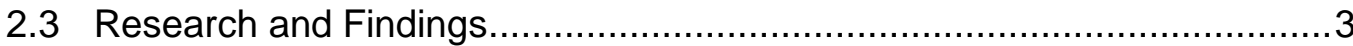

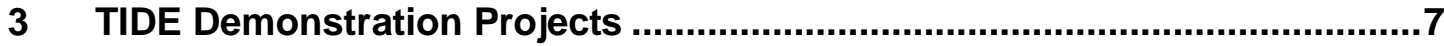

3.1 2D to 3D CAD Conversion ..............................................................

3.2 Adopting Automatic Scheduling and Simulation Tools.............................

3.3 Adopting 3D CAD and CAE Tools ....................................................

3.4 Adopting a Control-System-Modeling Tool ......................................... 8

3.5 Adapting Ecommerce and Manufacturing Execution System .................... 8

3.6 Testing Application Service Provider Paradigm for SMEs ........................8

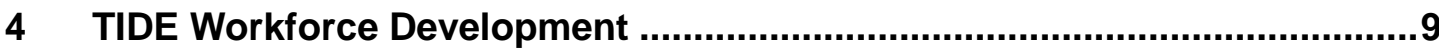

5 TIDE Technology Development ................................................................ 11

5.1 Operationally Critical Threat, Asset, and Vulnerability Evaluation ${ }^{\mathrm{SM}}$

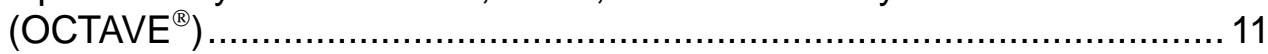

5.2 Advanced Engineering Environments .............................................. 11

$6 \quad$ Addressing Barriers and Constraints .....................................................13

6.1 Barrier: Lack of Information ......................................................... 13

6.1.1 TIDE Activity ............................................................. 13

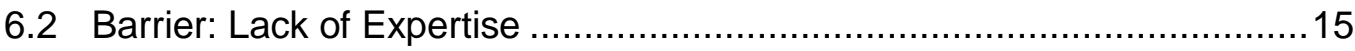

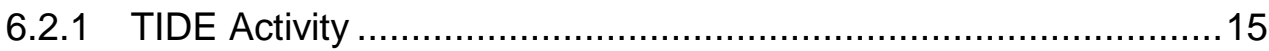

6.3 Barrier: Perception that Technologies Are Unaffordable ......................... 15 


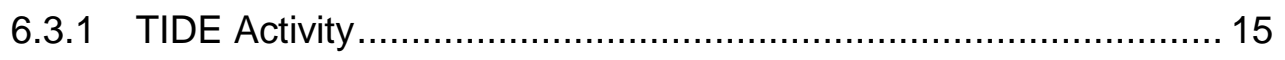

6.4 Barrier: Pressure to Be Productive ............................................... 17

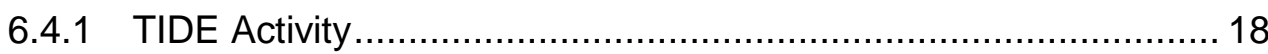

6.5 Barrier: Lack of Fit.................................................................... 19

6.5.1 TIDE Activity ............................................................ 19

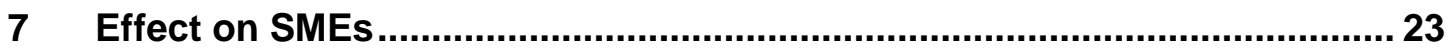

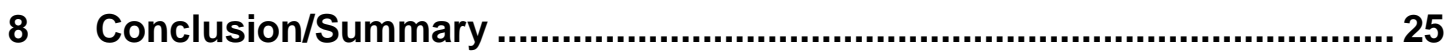

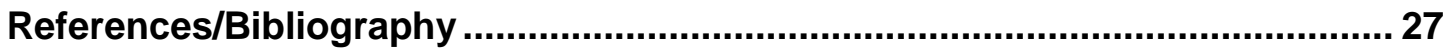




\section{List of Figures}

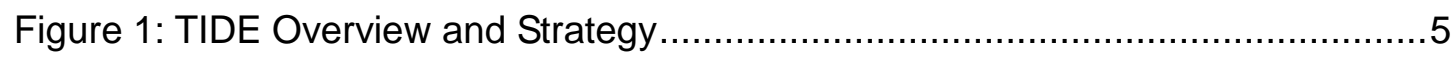

Figure 2: Technology Adoption Plan............................................................14

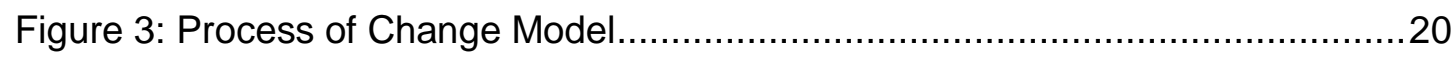


CMU/SEI-2003-TR-012 


\section{List of Tables}

Table 1: Process Change Steps and Communications Mechanisms .......................20 


\section{Acknowledgements}

The authors gratefully acknowledge Bill Anderson, Chuck Buhman, Joe Elm, John Robert, and Fred Shenker for their generous assistance in preparing this report. 


\section{Executive Summary}

Small manufacturing enterprises (SMEs) are critical to the defense industry of the United States. According to the National Coalition for Advanced Manufacturing (NACFAM), SMEs account for $20 \%$ of the prime contracts and $40 \%$ of the subcontracts awarded by, or on behalf of, the Department of Defense. Suppliers, especially small businesses, also generate $80 \%$ or more of the manufacturing value-added of some weapon systems.

Nevertheless, data from NACFAM and other organizations indicate that many SMEs are unable to support the defense industry. These SMEs lack required technologies such as computer-aided design, engineering and manufacturing systems, high-speed communication networks, and enhanced process management and control tools.

The Technology Insertion Demonstration and Evaluation (TIDE) Program was established to strengthen SMEs' ability to adopt technologies important to defense manufacturers. The TIDE program conducts demonstration projects, workforce development, and technology development activities to document the benefits of these technologies and the steps needed to implement them. 


\section{Abstract}

Small manufacturing enterprises (SMEs) are critical to the defense industry of the United States. SMEs account for an average of $20 \%$ of the prime contracts and $40 \%$ of the subcontracts awarded by, or on behalf of, the Department of Defense. Suppliers, especially small businesses, also generate $80 \%$ or more of the manufacturing value-added of some weapon systems. Nevertheless, data from the National Coalition for Advanced Manufacturing (NACFAM) and other organizations indicate that many SMEs are unable to support the defense industry because they lack the required technologies. This report summarizes technology demonstrations, workforce development activities, and technology development efforts of the Technology Insertion Demonstration and Evaluation Program. The knowledge gained from these activities can help SMEs to overcome technology adoption barriers and acquire the capabilities that the defense industry requires. 


\section{SMEs and the Defense Industrial Base}

Small manufacturing enterprises ${ }^{1}$ (SMEs) are critical to the defense industry of the United States. SMEs account for an average of $20 \%$ of the prime contracts and $40 \%$ of the subcontracts awarded by, or on behalf of, the Department of Defense (DoD) [NACFAM 02]. According to the DoD ManTech Program, suppliers, especially small businesses (500 employees or fewer), also generate $80 \%$ or more of the manufacturing value-added of some weapon systems.

As important as suppliers and SMEs currently are to the defense industrial base, indications are that their importance is increasing. In Defense Manufacturing in 2010 and Beyond, the National Research Council (NRC) reported that defense manufacturers have been involved in a wave of mergers and consolidations over the last several years. For example, between 1985 and 1995, Lockheed Martin acquired or merged with General Dynamic Space Systems, RCA, GE Aerospace, Gould Ocean Systems, Sanders, Loral, Goodyear Aerospace, LTV Missiles, IBM Federal Systems, Unisys Defense, Fairchild West, and Ford Aerospace, among other organizations [NRC 99]. Consolidation has reduced production capacity, leaving SMEs and larger manufacturers to take up the slack.

In addition, major defense contractors are concentrating on value-added activities such as program management, system engineering, system integration, and system-test services. As a result, they are outsourcing much of their planned production to qualified suppliers. For example, Boeing is the prime contractor for the Joint Direct Attack Munition (JDAM) "smart bomb," yet the DoD ManTech Program reports that $95 \%$ of the JDAM components come from Boeing's suppliers.

Another trend affecting SMEs is the emergence of the supply-chain paradigm. For example, to participate in a supply chain, defense manufacturers are calling on SMEs to collaborate in developing products, managing and providing just-in-time inventory, and producing nearperfect quality [Boden 99]. These activities, in turn, require computer-based design, engineer-

1 A small business is defined by the Small Business Administration in the Federal Register (Title 13, Chapter 1, Part 121). The definition also appears in the Federal Acquisition Regulation (19.101). Depending on the type of product called for by the contract, a company may qualify as a small business as long as it, or its affiliates, does not employ more than a specified number of employees (usually not more than 500, 750, or 1,000.) For construction and some service industries, the criterion is a specified annual dollar volume of sales or receipts rather than the number of employees. [NACFAM 02]. 
ing, and manufacturing systems, high-speed communication networks, and enhanced process management and control. Large defense manufactures and leading SMEs already have these capabilities; however, many SMEs still do not.

In "Contributions of and Issues Concerning Small and Medium Size Manufacturers in the Defense Industrial Base,” NACFAM called for strengthening the SME supplier base:

Critical shortages of spare part and component production capacity for aging weapon systems. Spare parts of Navy and Air Force aircraft and engines are frequently unavailable and manufacturing issues are cited as a direct reason for these shortages about one-third of the time. Change in the SME production base is one cause and changes to the SME production base may provide solutions to these challenges.

\section{Maintaining sufficient surge production capacity to meet unanticipated} national defense needs. The ability to rapidly expand production of platform systems, components, and munitions is constrained not only by the surge capacity of the prime contractor, but also by the capabilities of the supplier base. Given that the SME base diversified its customer base in the 1990s in response to the downturn in the federal defense budget, these firms may have greater resistance to working with the DOD's cumbersome acquisition process.

Modernizing SME techniques and manufacturing systems. Outdated and aging manufacturing systems and processes are present in the production processes of major weapons systems. With current plans calling for key aircraft, ground, and naval systems to be in service for many years to come, the shortage of capable SMEs will only become more acute.

Increasing the productivity of the SME supplier base. The largest defense companies have the ability and resources to make investments in productivity and efficiency improvements. SMEs frequently lack the necessary technical knowledge, staff, and resources to take advantage of new techniques and technology.

\section{Adapting commercial production practices and techniques in the defense SME base. Small manufacturers do not have the staff or technical expertise to identify potentially beneficial practices and may lack the knowledge needed to successfully implement them expeditiously. [NACFAM 02].}

The Technology Insertion Development and Evaluation (TIDE) Program was established to address the software technology needs of SMEs and the defense industry. 


\section{TIDE Program: Charter and Activities}

\subsection{The TIDE Mission}

The TIDE program helps improve the ability of SMEs to support defense manufacturers by demonstrating the benefits of implementing commercially available software and information technologies. While TIDE is focused on SMEs that supply goods and services important to national defense, much of the work of the TIDE program is broadly applicable to all small businesses.

\subsection{TIDE Organization and Operation}

The TIDE program is managed by the Software Engineering Institute ( $\mathrm{SEI}^{\mathrm{SM}}$ ) at Carnegie Mellon University (CMU) and coordinates the activities of a number of participants, such as the H. J. Heinz School of Management and Public Policy at CMU, the Institute for Economic Transformation at Duquesne University, National Institute of Standards and Technology (NIST), and the Southwestern Pennsylvania Industrial Resource Center (now called Catalyst Connection.)

\subsection{Research and Findings}

Small manufacturing enterprises differ from large organizations in many ways. For example, SMEs have the following qualities [Thong 97]:

- Simple and highly centralized structures, with the owner or CEO making most decisions. SME managers often know their products, market, and customers. However, they may not understand the relationship among business and operational processes, the software technologies that can streamline those processes, or the ability of those technologies to serve as a strategic asset. In essence, they do not perceive information technology as part of their "core" manufacturing business. In addition, the typical SME owner or manager may be actively involved in sales, production, human resources, accounting, and many other functions. As a result, he or she is too busy running the company to learn about advanced software-based tools and technologies, much less engaged in the decision-making processes required to implement them.

\footnotetext{
${ }^{\mathrm{SM}} \mathrm{SEI}$ is a service mark of Carnegie Mellon University.
} 
- Limited financial resources. Financial pressures force managers to focus on short-term opportunities or problems. These pressures also force managers to choose information technology (IT) equipment based on cost, rather than capability or "fit" with the organization. Limited financial resources also prevent SME managers from hiring experienced IT personnel.

- Generalist employees instead of specialists. If SME owners or managers often wear many hats, so do their employees. These generalists may not have time to follow advances in technology. They also may lack the skills, experience, or resources necessary to select, adopt, or implement software tools.

- Informal rules and infrastructures. Small companies often rely on tribal knowledge, i.e., a mixture of experience and expertise transmitted from one worker to another. They typically do not have set rules or infrastructures for decision-making. Often, they do not document, or clearly communicate, operating procedures to employees or vendors. As a result, it may be difficult to accurately predict the effect of advanced software technologies on the organization.

These organizational and operational limitations often manifest themselves as barriers or constraints. For example, Thong categorized these barriers into time, financial, and expertise [Thong 97]. Enzenhofer's list of internal barriers to technology adoption and transfer included unstructured procedures for analyzing SME needs, vague implementation practices, difficulties in identifying appropriate systems, difficulties understanding vendor systems, and excessive time needed to make IT decisions [Enzenhofer 01].

To verify these findings, TIDE sponsored a survey of 200 SMEs in Southwestern Pennsylvania as well as two focus groups with SME executives. The research indicates that $80 \%$ of the barriers to technology adoption were non-technical. These barriers included management's tendency to view software as an expense rather than as a strategic asset, the attitude that advanced technologies are not required or cost-effective, and the fear that technology would decrease productivity, rather than increase it.

The research and the experience of participating organizations led TIDE researchers to organize technology adoption barriers into five categories:

1. lack of information

2. lack of expertise

3. perception that SME cannot afford technologies

4. pressure to become productive

5. lack of fit

These barriers are often linked. For example, a manager might perceive that advanced software technologies are too expensive. This feeling may be based on the expense of a particular software product. However, the manger's perception might be caused by a lack of information about return on investment (ROI) of advanced software. 
If the barriers are often intertwined, so are the solutions. To overcome the financial barrier, an SME manager may need an affordable software package. Yet the manager may also need to consider the amount of training required and the impact that would have on operations. The TIDE program responded to this reality with demonstration projects, workforce development efforts, and technology development activities. The following graphic illustrates the relationship between TIDE activities and shows how the resulting body of knowledge can help SMEs streamline their own technology adoption efforts.

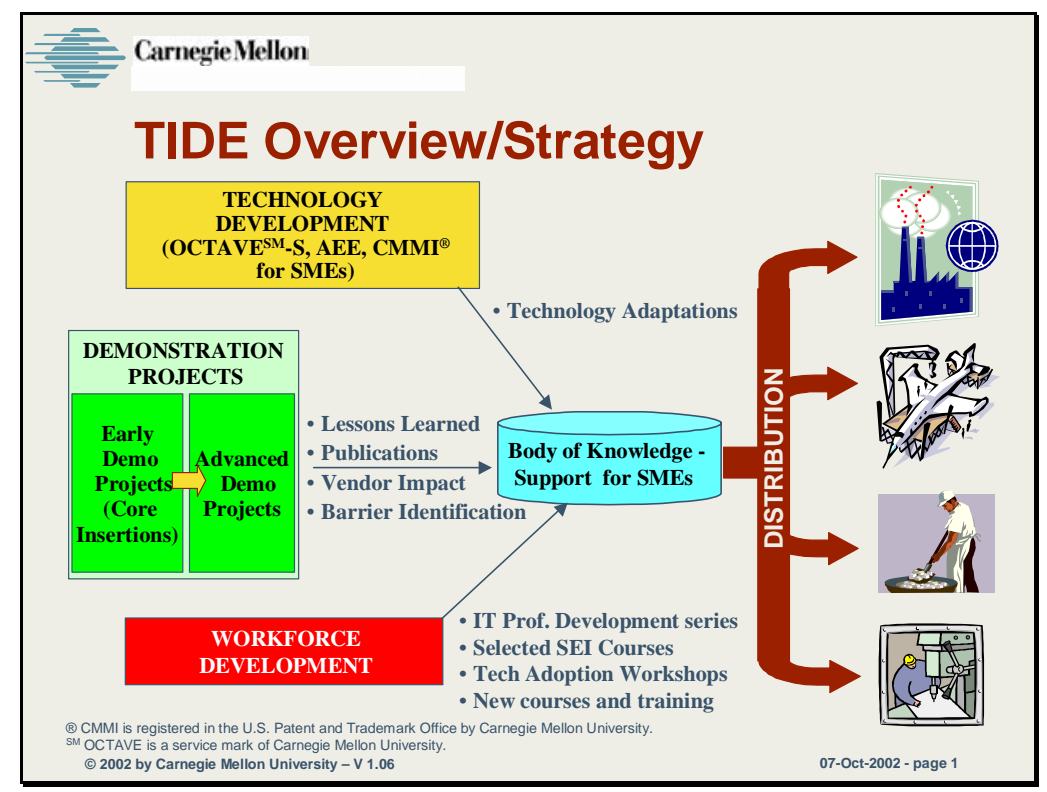

Figure 1: TIDE Overview and Strategy

The following sections in this technical report describe TIDE demonstration projects, workforce development and technology development initiatives and relate them to common adoption barriers. 
CMU/SEI-2003-TR-012 


\section{TIDE Demonstration Projects}

To encourage area SMEs to adopt advanced software technologies, the TIDE program conducted six demonstration projects with SMEs in Southwestern Pennsylvania. TIDE personnel supplied technical assistance. In exchange, the SMEs made their records, processes, and facilities available to TIDE researchers and staff members.

\subsection{D to 3D CAD Conversion}

Kurt J. Lesker Company (KJLC) is a family-owned firm with approximately 250 employees. KJLC manufactures ultra-high vacuum components and systems for a wide range of commercial and research applications. Company management had developed a strategy to pursue very complex, high-end systems business. To achieve that goal, they decided to upgrade from a 2D mechanical drafting tool to a 3D CAD package. TIDE personnel helped KJLC to define company needs, evaluate commercial products, and deploy the software. Based on productivity improvements, the company projected a 100\% return on its investment within 12 months.

\subsection{Adopting Automatic Scheduling and Simulation Tools}

TIDE personnel are working with KJLC to adopt a manufacturing execution system (MES) capable of producing bills of materials, process routings, resource management, and traceability from receipt-of-orders through shipping. The MES will be integrated with an automated production scheduling tool based on software originally developed for the U.S. Air Force. The tool will provide dynamic production scheduling capabilities.

\subsection{Adopting 3D CAD and CAE Tools}

Carco Electronics manufactures multi-axis rotational devices used to test inertial navigation and missile-seeker systems. To compete against much larger organizations, company management needed to improve the firm's engineering capabilities and customer responsiveness. TIDE personnel helped them to integrate a finite element analysis (FEA) tool into their existing 3D CAD system and to optimize their design process to take advantage of the new software. Based on the results, the company achieved a 100\% return on investment within 12 months. 


\subsection{Adopting a Control-System-Modeling Tool}

TIDE also helped Carco deploy a state-of-the-art modeling and simulation package to design complex digital control systems. The simulation tool included links to Electronic Design Automation (EDA) tools that simplified implementing the design in hardware and software.

\subsection{Adapting Ecommerce and Manufacturing Execution System}

Magdic Precision Tool is a 20-employee job shop that both designs and manufactures compaction tooling for the powdered metal industry. Magdic wanted to improve customer relations by reducing product-delivery cycle time. To achieve this goal, it implemented an MES. The system automates quote-generation, order-processing workflow management, performance analysis, and accounting functions. Ultimately, it will enable Magdic to implement a paperless manufacturing environment complete with Web-based, vendor-supplier communications.

\subsection{Testing Application Service Provider Paradigm for SMEs}

Internet service provider Stargate Industries and Shoptech Industrial Software Corporation are working with the TIDE program to offer on-line MES. It will allow small manufacturers who could not afford to purchase an entire MES to take advantage of its capabilities. This effort is designed to evaluate the Application Service Provider (ASP) business model as a means of serving SMEs. Further information will be published as it becomes available. 


\section{TIDE Workforce Development}

In addition to the demonstration projects, the TIDE program promoted workforce development through publications, training courses, and workshops. For example, the TIDE program presented a series of courses called Foundations of Information Technology. The ten-course program presented fundamental concepts in hardware and software components selection, IT systems management, IT security, and other issues. Students who successfully completed all ten courses received a Certificate in Information Technology Management.

TIDE also sponsored several courses and workshops, among them:

- Concepts and Trends in Information Security

- Continuous Risk Management

- Beyond the Vendor Checklist: Managing Risk in Software Technology Adoption

- Beyond Installation: Achieving Successful Software Technology Adoption

- Engineering Success for Small Enterprises

To help disseminate its growing body of knowledge, the TIDE program sponsored TIDE Conference 2002. The presentations and tutorials addressed both the technical and educational barriers facing SME managers and employees.

In addition, TIDE personnel have published articles in the business and trade press, including Dynamic Business Magazine, Manufacturing Magazine, National Defense Magazine, Pittsburgh Business Times, Pittsburgh Post-Gazette, Pittsburgh Tribune-Review, TEQ Magazine, and others.

TIDE personnel are also publishing a number of technical reports. These reports have been presented at the Defense Manufacturing Conference (DMC) 2002, the International Conference on COTS-Based Software Systems, and other events. 


\section{TIDE Technology Development}

In its third initiative, TIDE researchers modified software tools and practices to meet SME needs.

\subsection{Operationally Critical Threat, Asset, and Vulnerability Evaluation ${ }^{\mathrm{SM}}$ (OCTAVE $^{\circledR}$ )}

Exchanging information between vendors and suppliers puts the confidentiality, integrity, and availability of that data at risk. Most methods for evaluating information security were designed for large organizations. To address this issue, TIDE personnel modified the Operationally Critical Threat, Asset, and Vulnerability Evaluation ${ }^{\text {SM }}$ (OCTAVE ${ }^{\mathrm{SM} \circledast}$ ) method developed by the SEI. Currently in the final stages of development, OCTAVE-S provides an efficient, inexpensive approach to identifying and managing information security risks. Using the insight provided by OCTAVE, managers can protect information assets, communicate business and security needs, direct enterprise-wide risk assessments, and develop practice-based risk mitigation and protection strategies.

\subsection{Advanced Engineering Environments}

Advanced Engineering Environments (AEEs) consist of design tools (such as CAD and CAE), data repositories (such as design databases and evolution databases), and the networks linking these components and other enterprise processes. AEEs can improve productivity and product quality, while reducing product development time, production time, product cost, and development cost. AEEs can also help SMEs to rapidly changing customer demands and competitive environments.

SM Operationally Critical Threat, Asset, and Vulnerability Evaluation is a service mark of Carnegie Mellon University.

(B) OCTAVE is registered in the U.S. Patent and Trademark Office by Carnegie Mellon University. 


\section{Addressing Barriers and Constraints}

The following sections represent our efforts to help participating SMEs avoid or eliminate common technology adoption barriers. Other solutions may be just as valid. How a particular SME addresses these barriers will depend on the circumstances and resources available.

\subsection{Barrier: Lack of Information}

This category covers a lack of awareness of available software technologies, their capabilities, benefits, and return on investment. This category also includes a lack of knowledge about technology selection, adoption, and implementation as well as a lack of knowledge in organizational development and strategic planning.

\subsubsection{TIDE Activity}

Under the TIDE program, SME managers submitted ideas for demonstration projects. TIDE researchers evaluated each SME, its idea and its ability to successfully implement the proposed technology. TIDE personnel then worked with selected SMEs to achieve agreed-upon goals.

For example, the process improvement team at Magdic Precision Tooling approached the TIDE program for help developing an electronic document display capability. However, after reviewing their proposal and the firm's needs, the TIDE team suggested that Magdic implement an MES instead. The MES, in addition to solving the problem of document management, would automate quote-generation, order processing, workflow management, performance analysis, and accounting functions. To help Magdic personnel learn about the MES, TIDE personnel provided material on MES capabilities, benefits, and typical return on investment. TIDE staff members also helped Magdic to review and compare various products.

The MES and awareness issues were addressed within the context of a technology adoption plan shown in Figure 2: 


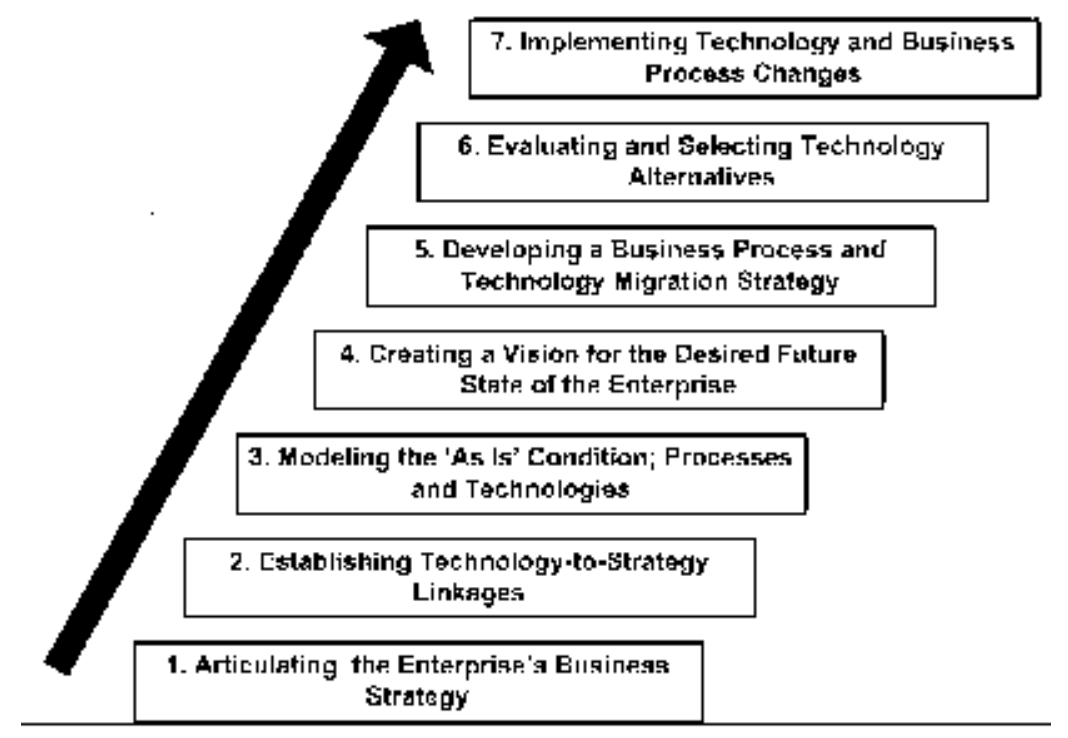

Figure 2: Technology Adoption Plan

Under the seven-step plan, Magdic

1. articulated its business strategy

2. linked that strategy to technologies it required

3. baselined its current business processes and operational practices

4. developed a vision for the future by applying their knowledge of the MES

5. prepared a business process and technology migration roadmap to achieve its vision

6. evaluated and selected the most appropriate technology products

7. implemented the changes

The technology adoption plan enabled Magdic to successfully select, adopt, and implement the MES. In turn, the MES has helped Magdic to

- streamline document management

- improve responsiveness to customers

- reduce total cycle times

- optimize shop scheduling

- increase shop capacity and throughput

TIDE team members used the technology adoption plan on several demonstration projects. In each case, it provided the information and infrastructure that SME managers required to overcome the lack of knowledge. The TIDE program also addressed lack of knowledge issues through courses, workshops, and tutorials. These activities helped SMEs make the most of their in-house capabilities. 


\subsection{Barrier: Lack of Expertise}

While SME managers typically have a high-level understanding of their business and operational processes, they often lack employees with the experience and skills necessary to adopt software technologies [Robert 03]. Furthermore, SME managers often spend their time on activities that directly affect their bottom line. As a result, they do not spend a lot of time on strategic planning. Yet charting a course for their company is necessary to assure that the software technology contributes to the firm's short-term and long-term goals.

\subsubsection{TIDE Activity}

TIDE staff members helped SMEs identify sources to supplement their lack of expertise. For example, TIDE personnel brought in a representative from the Institute for Economic Transformation (IET) at Duquesne University to assist Carco management with strategic planning. The consultant helped Carco to clarify its business goals and decide which technologies the company required. The consultant also helped Carco to refine its business processes to take advantage of the software.

Similarly, the IET consultant helped KJLC to document business processes as part of its effort to implement an MES with dynamic scheduling capability. In addition, a technology transition specialist from the SEI conducted a half-day workshop on technology adoption to address outstanding issues.

To make SME managers aware of the resources available, economic development, business development, commercial firms, and other organizations participated in the TIDE 2002 Conference as exhibitors.

\subsection{Barrier: Perception that Technologies Are Unaffordable}

An SME focus group conducted for the TIDE program revealed that managers often view advanced technology as an expense rather than a strategic investment. The focus group also revealed that SME managers are apprehensive about adopting the wrong hardware or software. They also fear that technology adoption can be a never-ending process; one that causes expenses to spiral out of control. The common thread is that many SME executives feel that they cannot afford advanced technologies, whether or not their feelings are valid.

\subsubsection{TIDE Activity}

SMEs typically obtain ROI data from a variety of sources, including manufacturers, valueadded resellers (VARS), magazine articles, and consultants. However, these sources may not 
be totally unbiased. Vendors, for example, choose the most successful case studies to help them sell software. These implementations may represent the exception rather than the rule. Similarly, executives may portray their successes in the most favorable light to impress their managers. Consultants obviously want to secure new business.

The TIDE program responded to the affordability issue by

- documenting direct benefits and ROI of advanced technologies in an unbiased manner

- helping SMEs view software as a strategic asset

- demonstrating ancillary benefits and their affect on ROI

- $\quad$ suggesting cost-effective ways to implement advanced software technologies

In one effort, TIDE personnel helped KJLC to replace its 2D mechanical drafting software with an advanced 3D CAD program. Company engineers used the software to create four standard platforms that could be modified to customer needs. As a result, TIDE personnel found that KJLC slashed design and engineering time by a factor of 10:1. The software also helped KJLC cut delivery times by $40 \%$, costs by $30 \%$, and prices by $20 \%$.

In another documented case, TIDE helped Carco adopt a solid modeling system. As part of a demonstration project, TIDE team members conducted three training programs on solid modeling and FEA. TIDE personnel also helped Carco engineers increase network bandwidth to improve modeling speed. They also doubled the number of software licenses. As a result, Engineering Change Notices dropped from 15 per project to one. Drafting and design time were reduced $25 \%$. Turnaround time for solid model drawings dropped from weeks to days.

In addition to demonstrating the benefits and ROI of advanced technologies, TIDE researchers helped SMEs view technology adoption as a strategic investment. For example, Carco Electronics originally installed its 3D solid modeling software to prevent rework during assembly. However, TIDE personnel encouraged the company to take a more strategic approach and look for additional ways to take advantage of the software's benefits and capabilities. As a result, Carco designers began to

- send computer-aided manufacturing files to sub-contractors and suppliers to improve component quality and reduce turn-around time

- exchange computer-aided design files with customers to strengthen their relationship

- use visualization models in their new business presentations

- perform a finite element analysis for one of its customers, opening up the possibility of a new income stream

The TIDE team also documented ancillary benefits, such as the tendency for each technology implementation effort to "naturally" lead to another. For example, after Carco Electronics implemented its 3D Computer-aided Drafting (CAD) and Finite Element Analysis (FEA) 
tools, company engineers looked at a computer-aided engineering (CAE) tool set. It would eliminate the need to physically prototype and test design iterations. Instead, Carco engineers could develop the control system, simulate and analyze its performance, and model control system-device integration throughout the product development life cycle.

Carco engineers purchased and used the tool set on a new product development effort. The tool set significantly reduced new product development costs, yielding an ROI of five to one on the first project alone. It also allowed engineers to develop and patent a new control algorithm, which could not have been developed any other way. The ROI generated by the CAE toolset grew out of Carco's original decision to adopt CAD.

Similarly, TIDE personnel documented benefits that resulted from Magdic's decision to implement an MES. The MES forced Magdic personnel to continually enter complete, timely, and accurate information early in the production process. They could no longer "fudge" figures initially and enter accurate numbers later. This, in turn, reduced errors and increased throughput. It helped executive managers make better decisions. It allowed shop floor managers to prioritize jobs and plan ahead. Finally, it enabled the company to offer better service by allowing managers to accurately respond to customer requests.

In another activity designed to address affordability, TIDE personnel conducted several product implementations and evaluations using the PLAN, ESTABLISH, COLLECT and ANALYZE (PECA) method. The methodology helped Magdic engineers to identify and prioritize needs and evaluate prospective software packages against those needs. In this way, TIDE helped Magdic obtain the most appropriate and cost-effective software package. TIDE personnel also helped Magdic to choose an MES that would work with its legacy systems. This encouraged Magdic to install several thin client terminals on the shop floor, rather than installing more expensive PCs.

At Carco, TIDE staff members helped company personnel to avoid purchasing additional licenses for its high-end CAD software. At the time, designers and engineers were "competing" for access. To resolve the problem, TIDE personnel recommended that Carco purchase a "light" CAD software package. It did not have the functionality of the full-blown CAD software, yet engineers still could use it for preliminary tasks. The light CAD version settled the issue of contention at a fraction of the cost of the complete software package.

\subsection{Barrier: Pressure to Be Productive}

SMEs typically run lean operations. Owners and employees have multiple responsibilities and perform multiple tasks. Time is a limited and, therefore, precious commodity. SME managers are under tremendous pressure to be productive. As a result, they may feel that they do 
not have time to experiment with new systems or to "wait" for the system to pay for itself. Instead, they must focus on activities or purchases that directly affect profitability.

\subsubsection{TIDE Activity}

TIDE staff members addressed this throughout the seven-step technology adoption planning process. For example, relating technologies to business goals allowed managers to see the potential of technology adoption. Identifying "as is" and "to be" visions of the company showed managers the expected impact. Furthermore, developing a technology adoption roadmap eliminated unnecessary tasks and avoided "wheel-spinning."

The KJLC project to develop an automated production scheduling system illustrates this approach. As part of the technology adoption process, TIDE personnel helped the managers map activities, decisions and regular meetings for a range of company functions. The map for one function, for example, incorporated the sales, product manager, engineering, accounting, and shipping departments.

The cross-functional maps detailed each "as is" process. At that point, TIDE personnel reviewed the process and recommended ways to improve it, either by modifying current processes or suggesting new processes that would take advantage of the MES.

In addition to evaluating business and operational processes, TIDE personnel tried to streamline product evaluation. In the first KJLC project, TIDE personnel asked potential vendors to demonstrate their software using "authentic" data and tasks. The vendor complied, loaded its software on a representative system, and watched KJLC personnel apply it. The demonstration was designed to prove that the software provided the capabilities and ease-of-use required. However, the demonstration also revealed a potential problem: a KJLC engineer had been adding his own notations to the project. The notations worked with KJLC's current 2D mechanical drafting software, but the new software didn't recognize the characters. After a brief investigation, the vendor found the source of the problem. Changing the format of the notation corrected it.

Using KJLC personnel, data, and representative tasks to demonstrate the software avoided this potential bottleneck. It also dramatically reduced time to become productive. In fact, the systems engineering team began successfully using the new tool within two weeks and achieved desired productivity within one month.

Similarly, TIDE personnel encouraged Carco to supplement the general training provided by the CAD vendor with in-house seminars on the software. Carco also paid for additional consulting on specific tasks. And Carco retained a service bureau to monitor the quality of the 
work being performed during training. These activities helped reduce the time needed to become productive by $50 \%$ over general training alone.

\subsection{Barrier: Lack of Fit}

For the most part, the advanced software tools used in the TIDE program were commercially available software tools. In general, commercial off-the-shelf (COTS) software requires companies to modify their processes and procedures to fit the software. However, if the required changes are very extensive and pervasive, they indicate a lack of fit. SMEs that have limited experience purchasing and implementing COTS software are particularly susceptible to this problem. In some cases, the SME may not have adequately trained people. In other cases, the software itself may not be appropriate for the job. However both scenarios can cause dissatisfaction and can discourage the SME from adopting critically needed software technologies in the future.

\subsubsection{TIDE Activity}

The TIDE program tried to assure fit promoting the seven-step technology adoption process shown in Figure 2. It allowed SME managers to examine the technology, organization, culture, and operational issues associated with the adoption process.

In addition to its seven-step technology adoption plan, TIDE personnel also addressed fit through workshops and tutorials. The tutorials were designed to identify the non-technical risks associated with software implementation.

For example, TIDE personnel and KJLC held an Adoption Risks/Planning Workshop to help the company address the complexity of the dynamic production scheduling MES and the changes it would cause. During the first part of the workshop, participants rated KJLC's current structure, values, skills, work practices, and other factors. This helped the company determine its readiness to implement the software. Participants also looked at potential risks and reviewed previous adoption efforts.

Once the group understood their "as is" condition, they collated and prioritized the risks. Then, the workshop participants looked at activities to mitigate risks. They used a process of change model, shown in Figure 3, to guide their efforts. 


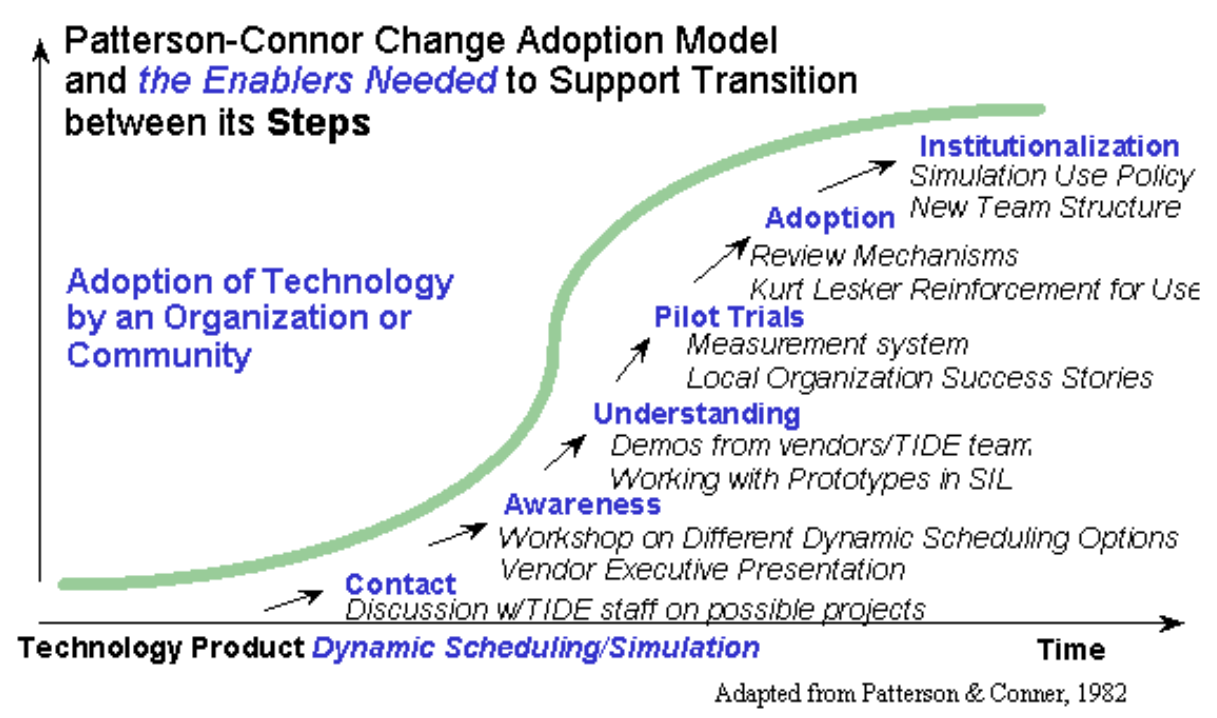

\section{Figure 3: Process of Change Model}

According to the process of change model, change evolves along a continuum of steps: contact, awareness, understanding, pilot trials, adoption, and institutionalization. ${ }^{2}$ As shown in Table 1 below, each step had its own support and communications mechanisms to mitigate risks and overcome barriers.

\section{Table 1: Process Change Steps and Communications Mechanisms}

\begin{tabular}{|l|l|}
\hline Change Model Process Steps & Support and Communications Mechanisms \\
\hline contact and awareness & corporate presentation, magazine articles, dedicated Web site \\
\hline understanding & $\begin{array}{l}\text { communication and education seminars, detailed case studies, identifying } \\
\text { stakeholder roles, responsibilities, and relationships }\end{array}$ \\
\hline trial use & $\begin{array}{l}\text { communication, education, and support activities, such as courses, user groups, } \\
\text { and pilot programs }\end{array}$ \\
\hline adoption & $\begin{array}{l}\text { incentives, rewards, consequences, guidance on software usage, sample im- } \\
\text { plementation plan, job aids, process guides, etc. }\end{array}$ \\
\hline institutionalization & training courses, cutover policy, continuous improvement plan \\
\hline
\end{tabular}

In addition, each step in the change model had its own definition of success and metrics criteria. For example, under contact and awareness, KJLC could track the number of people who attended meetings or received literature on the software. Ideally, these people should be able to answer the basic questions associated with the implementation such as: What are we doing? Why? Who should use this system? What will it do?

2 This change model is adapted from one that appeared in an article by Daryl R. Conner and Robert W. Patterson titled "Building Commitment to Organizational Change." It was published in the April 1982 issue of Training and Development Journal. 
The Adoption Risks/Planning Workshop also offered guidance on maintaining employee involvement once the software had been fully implemented. The workshop ended by listing the steps that KJLC took to actualize the concepts presented. These steps included:

- determining level of use goals for the dynamic scheduling system

- determining implementation progress measurement events

- completing/approving the communications plan

- defining/approving the process for monitoring and managing adoption risks

The Adoption Risks/Planning Workshop helped the employees "get on the same page." It prevented misunderstandings, clarified objectives, and established measurable guidelines for results. KJLC is still implementing the MES in stages and reviewing their progress against milestones. At a recent meeting, however, TIDE and KJLC personnel reviewed their initial list of risks and barriers. Many had "gone away" as a result of the activities suggested during the workshop. 


\section{Effect on SMEs}

The TIDE program benefited SMEs in several ways. First, participating SMEs at improved their ability to support the defense industry supply chain and compete in a global economy. For example, Carco used its new design software to develop and patent a unique algorithm that has a variety of defense applications. Similarly, KJLC used its capability to design standard product configurations that slash the time required to respond to customers.

The SMEs also acquired valuable expertise. This will allow the companies to continue their technology adoption efforts. For example, Carco conducted a technology evaluation to determine its next software purchase. By applying the methods learned through TIDE, the company identified a strategic capability, examined candidate software packages, negotiated with the vendor to obtain the software they wanted, and implemented the package without help from TIDE personnel.

Furthermore, the body of knowledge gained can help other SMEs to avoid many pitfalls, while streamlining their efforts, and improving their chances of technology adoption success.

In the words of Kurt J. Lesker III, CEO of KJLC, "I cannot say enough about the program. They set out to make U.S. manufacturers more agile to adapt to the changing nature of the defense industry, and that's exactly what they have done" [Copeland 02]. 


\section{Conclusion/Summary}

Small manufacturing enterprises face a number of issues, risks, and barriers to adopting advanced software technologies. In general, these fall into five categories: lack of information, lack of expertise, perception that advanced technologies are not affordable, pressure to be productive, and lack of fit. The TIDE program addressed the issues, risks, and constraints associated with these categories through its demonstration projects, workforce development, and technology development activities.

\begin{tabular}{|c|c|c|}
\hline Barrier & Issue, Risk, Constraint & TIDE Response \\
\hline $\begin{array}{l}\text { Lack of Information/ } \\
\text { Expertise }\end{array}$ & $\begin{array}{l}\text { a. Unaware of software, benefits, } \\
\text { capabilities, ROI. } \\
\text { b. Lack of knowledge of how to se- } \\
\text { lect, adopt, and implement software. } \\
\text { c. Lack of knowledge of how to } \\
\text { evaluate organizational needs. } \\
\text { d. Lack of training in software use } \\
\text { and optimization. } \\
\text { e. Lack of knowledge of outside } \\
\text { sources of expertise. } \\
\text { f. Lack of strategic and tactical plan- } \\
\text { ning skills. }\end{array}$ & $\begin{array}{l}\text { a. Six demonstration projects } \\
\text { b. TIDE courses, workshops, tutori- } \\
\text { als, presentations } \\
\text { c. Papers, publications, and materials } \\
\text { d. TIDE } 2002 \text { Conference }\end{array}$ \\
\hline $\begin{array}{l}\text { Perception that SME Cannot } \\
\text { Afford Technologies }\end{array}$ & $\begin{array}{l}\text { a. SME "cannot afford" software e.g., } \\
\text { it is too expensive for the expected } \\
\text { return. } \\
\text { b. SME "cannot afford" technical } \\
\text { infrastructure (new computers/ net- } \\
\text { works that the software requires). } \\
\text { c. SME "cannot afford" training or } \\
\text { consulting. } \\
\text { d. Fear that expenses associated with } \\
\text { software will never end. } \\
\text { e. Fear of wasting money on software } \\
\text { or capabilities of no use. }\end{array}$ & $\begin{array}{l}\text { a. Documented ROI. } \\
\text { b. Showed how one technology leads } \\
\text { to another, and how the benefits cas- } \\
\text { cade through the organization. } \\
\text { c. Showed how to reduce expense of } \\
\text { software by matching software to } \\
\text { needs, purchasing software that will } \\
\text { take advantage of legacy systems, } \\
\text { purchasing a mix of equipment (PCs } \\
\text { and thin clients), negotiating for } \\
\text { needed software at favorable terms. }\end{array}$ \\
\hline
\end{tabular}




\begin{tabular}{|c|c|c|}
\hline Barrier & Issue, Risk, Constraint & TIDE Response \\
\hline Pressure to be Productive & $\begin{array}{l}\text { a. SME management perception that } \\
\text { they do not have time (or not worth } \\
\text { their time) to learn about software. } \\
\text { b. SME management does not have } \\
\text { time to organize and oversee imple- } \\
\text { mentation. } \\
\text { c. SME employees do not have time } \\
\text { for training. } \\
\text { d. SME can't wait for system to start } \\
\text { paying for itself. }\end{array}$ & $\begin{array}{l}\text { a. Promoted use of seven-step tech- } \\
\text { nology adoption process to eliminate } \\
\text { obstacles and wheel spinning. } \\
\text { b. Encouraged software vendors to } \\
\text { use customer data and systems in } \\
\text { their demonstrations. } \\
\text { c. Encouraged SMEs to obtain train- } \\
\text { ing on specific tasks and applications. }\end{array}$ \\
\hline Lack of Fit & $\begin{array}{l}\text { a. Organization not ready for soft- } \\
\text { ware. Employees may feel it is a nui- } \\
\text { sance or waste of time. They may be } \\
\text { afraid that they will not be paid or } \\
\text { judged according to previous stan- } \\
\text { dards. } \\
\text { b. Operations are not ready. Confu- } \\
\text { sion and conflict may exist between } \\
\text { departments over roles and responsi- } \\
\text { bilities. Business and production } \\
\text { processes may need to be modified to } \\
\text { meet software needs. } \\
\text { c. SME may not have proper systems } \\
\text { or networks. }\end{array}$ & $\begin{array}{l}\text { a. Promoted use of seven-step tech- } \\
\text { nology adoption process to eliminate } \\
\text { obstacles and wheel spinning. } \\
\text { b. Promoted use of Adoption/Risk } \\
\text { Planning workshop to identify issues, } \\
\text { barriers, risks, and develop activities } \\
\text { to mitigate or overcome them. }\end{array}$ \\
\hline
\end{tabular}




\section{References/Bibliography}

All URLs are valid as of June 2003.

[Boden 99]

[Copeland 02]

[Enzenhofer 01]

[NACFAM 02]

[NRC 99]

[Robert 03]
Boden, Brench. "White Paper: Initiative for Small and Medium Enterprises." <http://www.nwlean.net/sme.htm> (1999).

Copeland, David. "Keeping up with the Big Guys." Pittsburgh Tribune Review. April 27, 2002.

Enzenhofer, Wilfried \& Chroust, Gerhard. "Best Practice Approaches in Know-How and Technology Transfer Methods for Manufacturing SMEs," 279-286. Proceedings of the 27th EUROMICRO Conference. Warsaw, Poland, Sept. 4-6, 2001. Los Alamitos, CA: IEEE Computer Society, 2001.

National Coalition for Advanced Manufacturing. "Contributions of and Issues Concerning Small and Medium Sized Manufacturers in the Defense Industrial Base." Washington, D.C.: NACFAM, 2002. <http://www.nacfam.org/sme_concept.pdf >

National Research Council. Defense Manufacturing in 2010 and Beyond: Meeting the Changing Needs of National Defense. Washington, D.C.: National Academy Press, 1999.

Robert, John; Buhman, Charles; Garcia, Suzanne; \& Allender, David. Bringing COTS Information Technology into Small Manufacturing Enterprises, Pittsburgh, PA: Software Engineering Institute, Carnegie Mellon University, 2003.

[Thong 97]
Thong, J. Y. L. \& Yap, C. S. "Effects of Resource Constraints on Small Business," 191-206. International Working Conference on Diffusion, Adoption and Implementation of Information Technology, Ambleside, UK, June 25-27, 1997. London, UK: Chapman \& Hall, 1997. 


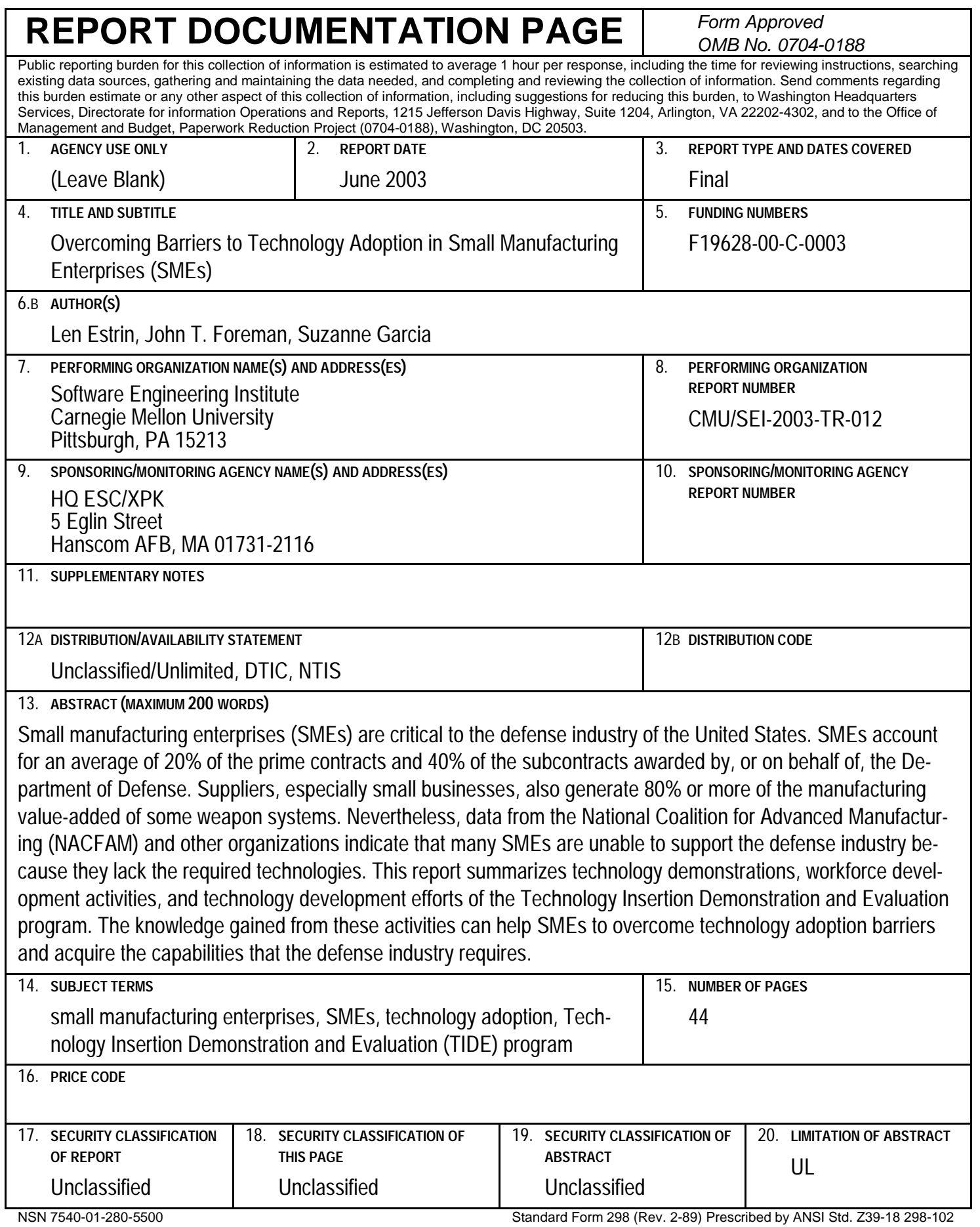

